\title{
ARCOBACTER SPECIES AND THEIR RISKS IN SOME MEAT AND FISH WITH A SODIUM ACETATE AND SODIUM CHLORIDE INTERVENTION
}

\author{
M.A.M. AMMAR and S.H. AL-HABATY \\ Animal Health Research Institute, Assiut Regional Lab. (AHRI), Egypt \\ Email: mahmoud2014eg@yahoo.com
}

Assiut University web-site: www.aun.edu.eg

\section{ABSTRACT}

Received at: $1 / 6 / 2015$

Accepted: 25/7/2015
A surveillance study of retail foods was conducted in Assiut, Egypt to assess the presence of Arcobacter spp. on retail food samples. A total of 75 fresh samples of beef, minced beef, and fish (Oreochromis niloticus), 25 each were purchased from fresh markets in Assiut city and tested for Arcobacter spp. The survey was carried out by differential culture, phenotying and genotyping. A total $35(47 \%)$ of samples was contaminated with Arcobacer spp. Beef was the most contaminated 13(52\%) followed by minced beef 12(48\%) then fish 10 (40\%). By genotyping using PCR, only a total $11(15 \%)$ of samples harbor Arcobacter spp. Five (20\%) of beef, $2(8 \%)$ of minced beef and $4(16 \%)$ of fish were contaminated with Arcobacter spp. When the isolates were confirmed by genus-based PCR, A. butzleri, A. skirrowii and A. cryaerophilus were present in a total $4(5 \%), 5(7 \%)$ and $2(3 \%)$ of examined retail foods. The highest $A$. butzleri contamination level was in beef samples 2 (8\%). $A$. cryaerophilus, A. skirrowii and A. butzleri were examined for their susceptibilities to antibiotics using a disk-diffusion method. All were resistant to Lincomycin, Vancomycin, Tetracycline. Cloxacillin, Cephradine, Novobiocin and Oxacillin but susceptible to Gentamycin and Neomycin. With the exception of A. cryaerophilus the tested Arcobacters were susceptible to Ciprofloxacillin. The effect of sodium acetate (SA) and sodium chloride (SC) on growth inhibition of Arcobacter spp. was investigated by determining the minimum inhibitory concentration (MIC) and the minimum lethal concentration (MLC). Sodium acetate provided overall greater inhibition in comparison with (SC). The MLCs were $6 \%$ and $9 \%$ for of (SA) and (SC), respectively. The corresponding MIC values were $4 \%$ and $6 \%$, respectively. The combined effect of (3\% SC) and SA at different concentrations $(0.01-0.05 \%)$ were tested against $A$. butzleri in the growth medium. A significant $(\mathrm{P}<0 \quad .05)$ reduction level of $A$. butzleri cells was obtained by the combination of $3 \%$ (SC) and 0.04 or $0.05 \%(\mathrm{SA})$. The greatest reduction $(2.7 \mathrm{log})$ was achieved by the combined effect of $3 \%$ (SC) and $0.05 \%$ (SA). In minced beef model, (3\% SC $+0.05 \% \mathrm{SA}$ ) mixture took $12 \mathrm{~h}$ to produce $1 \log$ reduction in the initial A. butzleri count and the reduction was proximate at $24 \mathrm{~h}$ period. The difference in A. butzleri count between treatment and control samples was significant $(\mathrm{P}<0.05)$. The present study identified beef and minced beef as important food sources of A. butzleri which pose a threat for human health. Also it cleared that fish at retail has been detected to be a further food matrix for A. butzleri. Regarding the enteropathogen A. butzleri, (3\% $\mathrm{SC}+0.05 \% \mathrm{SA}$ ) mixture can improve the safety of minced meat under refrigerate storage. This study also shows that Gentamycin would be drugs of choice and Neomycin as alternative for treatment of Arcobacter borne gastrointestinal infection in this geographical area. The public health significance of Arcobacter spp. and the control measures were also discussed.

Key words: Arcobacter spp., Beef, Fish, PCR, Antimicrobial, Susceptibility, Sod. chloride, Sod. acetate

\section{INTRODUCTION}

Meat is the first-choice of animal protein for human and consumption of meat is continuously increasing worldwide. The annual per capita consumption increased by 2.6 fold in 2000 and will increase by 3.7 fold by 2030 compared to that of 1960s, (Dave and Ghaly, 2011). Also meat and meat products are important sources of vitamins and minerals. They also may contain microorganisms which in certain circumstances and in inappropriate proportions can negatively affect human health. One 
of the most important aspects relating to some of the potential health problems associated with meat consumption is emerging pathogens, (Tarrant, 1998).

Arcobacters are members of the family Campylobacteraceae and phenotipically similar to Campylobacters. They differ from Campylobacters by their ability to grow under both aerobic conditions and under $30^{\circ} \mathrm{C}$. The importance of the genus Arcobacter lies in the fact that some species are considered emerging enteropathogens and potential zoonotic agents, (Kayman, 2012). Presently the genus Arcobacter includes a total of 15 species. Three species of Arcobacter have been recovered from man and animals: A. butzleri, A. cryaerophilus, and A.skirrowii, (On et al., 2002).

There is evidence that livestock animals may be a significant reservoir of Arcobacter spp. (Ho et al., 2006). Also, apart from A. nitrofigilis and other species of Acrobacter have been isolated from various animal diseases including abortion, septicaemia, mastitis, gastritis and enteritis (On et al., 2002).

On fecal samples collected at slaughterhouses in Belgium, Arcobacter spp. was isolated from $44 \%$ of porcine, $40 \%$ of bovine, and $16 \%$ of ovine samples. All three animal-associated Arcobacter spp. were isolated and levels of up to $10^{3} \mathrm{cfu} / \mathrm{g}$ feces were found, (Van Driessche and Houf, 2007). Also, investigations revealed that A.butzleri and $A$. cryaerophilus are commonly present on slaughter equipment (Houf et al., 2003). Arcobacter spp. were already isolated from a wide range of food of animal origin. The highest prevalence is reported for poultry meat, followed by pork and beef (Houf et al., 2002; Shah et al., 2011).

The prevalence of Arcobacter in shellfish has shown to be relatively high i.e. $100 \%$ in clams and $41.1 \%$ in mussels (Collado et al., 2009). As a result, it was suggested that shellfish should be considered another source of infection because they have an ability to concentrate bacterial pathogens from water and are often eaten poorly cooked or raw (Collado et al., 2009). However, little is known about the presence of Arcobacter in fish or fish meat.

The exact routes of human infection with Arcobacter are not clear, but probably include manipulation of raw meat, the consumption of undercooked products and cross-contamination, (Milesi, 2010). Clinical symptoms are similar to campylobacteriosis, but a higher frequency of persistent and watery diarrhea has been reported, (Vandenberg et al., 2004). Besides the correlation with gastro-enteritis, Arcobacter has also been implicated in extra-intestinal invasive diseases, (On et al., 1995 and Yan et al., 2000). Most of the reported cases of extra intestinal presentation involved bacteraemia and occurred in immunocompromised patients or those with indwelling devices (Collado and Figueras, 2011).

PCR assays to detect all members of the genus Arcobacter and that are specific for each Arcobacter species have been reported. Based on the knowledge of the Arcobacter nucleic acid composition of the 16S rRNA, and by means of five primers, a PCR product of 401-bp was generated for A. butzleri, 257-bp for $A$. cryaerophilus and 641-bp for A. skirrowii. Those three species were also identified by the PCR assay developed by ( Kabeya et al., 2003).

Minimizing product contamination and delaying or inhibiting growth of spoilage and pathogenic organisms in the product are major keys for improving fresh meat shelf life and increasing consumer safety. While general cleanliness and proper sanitation are very effective, other means of controlling microbial growth in meat products may be prove useful, (Lee et al.,1997).

Sodium chloride (SC) has been long used as a meat preservative. It is added to meats for its effects on sensory, functional and preservation properties. Sodium chloride inhibits the microbial growth by restriction of the available water (i.e. lowers ${ }^{a} w$ ) in the meat products. However, its pro-oxidant activity accelerates the development of lipid oxidation in refrigerated meats (Lee et al., 1997). Antioxidative effects of sodium organic salts derived from citric, lactic and acetic acids have already been studied on color and lipid oxidation in n-3 oil fortified ground beef patties (Lee et al., 2005).

Lately, the application of organic acids and their salts have been more considered due to their natural and appropriate antimicrobial properties. Acetic, lactic, propionic and sorbic acids and their salts exert antimicrobial activity. They have been traditionally used as food preservatives (Ray, 1996). Acetates increase the acidity of the environment where they are applied and so obstruct the growth of meat spoilage bacteria, (Dragoev, 2004). Also, it possessed antibacterial activity against some bacterial pathogens (Nanasombat and Chooprang, 2009).

Despite the role of raw meat in transmission of Arcobacter infection to consumers, the eventual presence of Arcobacters in beef at retail in Assiut have seldom been assessed also the distribution of Arcobacter spp. in fish is unknown. Therefore, the aim of this study was to evaluate the prevalence of Arcobacter spp. in raw beef, minced beef and fish, to genotype Arcobacter strains isolated from these sources using PCR and to study their antimicrobial susceptibility and their behavior in the presence of sodium chloride and sodium acetate in growth medium and meat model. 


\section{MATERIALS and METHODS}

\section{Collection of samples:}

A total 75 fresh samples of fish (Oreochromis niloticus), minced meat (250g portions) and beef ( $250 \mathrm{~g}$ portions), 25 samples each were purchased from retail shops throughout Assiut City, Upper Egypt. After purchase, the samples were placed in an ice cooler until they were delivered the laboratory. The examination of samples was as rapid as possible within half an hour. During this period, they were stored at $4-6^{\circ} \mathrm{C}$.

Isolation of Arcobacter spp.: (O"ngo"r et al., 2004) In case of fish, $25 \mathrm{~g}$ muscle samples were aseptically taken from the left hand side of each fish in the anterior dorsal region. Also, $25 \mathrm{~g}$ portion each of beef or minced beef were aseptically sampled. For each the samples were separately macerated in a sterile mortar without diluents. Then one gram sample was aseptically inoculated into $10 \mathrm{ml}$ Brucella broth (Difco, Detroit, MI, USA) with CAT supplement (Cefoperazone, $8 \mathrm{mg} / \mathrm{L}$; Amphotericin, $10 \mathrm{mg} / \mathrm{L}$ and Teicoplanin, $4 \mathrm{mg} / \mathrm{L}$, Oxoid, Basingstoke, UK) and mixed thoroughly by vortex. The homogenates was incubated aerobically at $30^{\circ} \mathrm{C}$ for $48 \mathrm{~h}$. These enriched samples were then plated onto MuellerHinton agar (CM337, Oxoid) supplemented with 5\% (v/v) lysed horse blood and CAT selective supplement. The plates were incubated aerobically at $30^{\circ} \mathrm{C}$ for 3 days. Arcobacter-like colonies (round, 2-4 $\mathrm{mm}$ grey to whitish) were picked for phenotyping according the standard biochemical tests recommended by (Kayman, 2012). The phenotypic characteristics of Arcobacter species were assessed based on Gram staining; productions of oxidase, catalase, urease, alpha-hemolysis; and growth at different conditions (at $30^{\circ} \mathrm{C}$, at $37^{\circ} \mathrm{C}$, at $42^{\circ} \mathrm{C}$, aerobically, microaerobically, and anaerobically).

\section{Identification of isolated strains by polymerase chain reaction (PCR): \\ 1- Primer_sequences_used for PCR system: \\ Specific 16S rDNA fragments for A. butzleri, A. skirrowii as well as for A. cryaerophilus were applied for demonstration and characterization of such strains by using the primers shown in (Table 1).}

Table 1: Primer sequences for Arcobacter spp. polymerase chain reaction

\begin{tabular}{|c|c|c|c|c|}
\hline Fragment & Primers & Oligonucleotide sequence $\left(5^{\prime} \rightarrow 3^{\prime}\right)$ & $\begin{array}{c}\text { Product size } \\
\text { (bp) }\end{array}$ & References \\
\hline \multirow{2}{*}{$\begin{array}{l}\text { A. butzleri } \\
16 \mathrm{~S} \text { rDNA }\end{array}$} & BUTZ (F) & 5' CCTGGACTTGACATAGTAAGAATGA '3 & \multirow[b]{2}{*}{401} & \multirow{2}{*}{$\underset{(2000)}{\text { Houf }}$ et al., } \\
\hline & $\overline{\mathrm{ARCO}(\mathrm{R})}$ & 5' CGTATTCAACCGTAGCATAGC ' $\mathbf{3}$ & & \\
\hline \multirow{2}{*}{$\begin{array}{l}\text { A. skirrowii } \\
16 \mathrm{~S} \text { rDNA }\end{array}$} & SKIR (F) & 5' GGCGATTTACTGGAACACA '3 & \multirow[b]{2}{*}{641} & \multirow{2}{*}{$\underset{(2000)}{\text { Houf }}$ et al., } \\
\hline & $\overline{\mathrm{ARCO}(\mathrm{R})}$ & 5' CGTATTCACCGTAGCATAGC ' $\mathbf{3}$ & & \\
\hline \multirow{2}{*}{$\begin{array}{l}\text { A.cryaerophilus } \\
16 \mathrm{~S} \text { rDNA }\end{array}$} & CRY1 (F) & $\mathbf{5}^{\prime}$ TGCTGGAGCGGATAGAAGTA '3 & \multirow{2}{*}{257} & \multirow{2}{*}{$\underset{(2000)}{\text { Houf }}$ et al., } \\
\hline & CRY2 (R) & 5' AACAACCTACGTCCTTCGAC '3 & & \\
\hline
\end{tabular}

2. DNA Extraction using QIA amp kit: (Shah et al., 2009)

After overnight culture on nutrient agar plates, one or two colonies were suspended in $20 \mathrm{ml}$ of sterile distilled water, and the suspension was then heated at $100^{\circ} \mathrm{C}$ for 20 minutes. Accurately, 50-200 $\mu 1$ of the culture were placed in Eppendorf tube and the following steps were carried out:

2.1. Equal volume from the lysate $(50-200 \mu \mathrm{l})$ was added, addition of $20-50 \mu 1$ of proteinase $\mathrm{K}$, then incubation at $56^{\circ} \mathrm{C}$ for $20-30 \mathrm{~min}$.

2.2. The solution was added to the column and centrifuged at $8000 \mathrm{rpm}$ for $1 \mathrm{~min}$. then the filtrate was discarded.

2.3. The sediment was washed using AW1 buffer $(200 \mu \mathrm{l})$, the column was centrifuged at $8000 \mathrm{rpm} / 1$ min, and the filtrate was discarded.
2.4. Washing was applied by using the AW2 buffer $(200 \mu \mathrm{l})$, the column was centrifuged at $8000 \mathrm{rpm} / 1$ min. and the filtrate was discarded.

2.5. The column was placed in a new clean tube then, 25-50 $\mu 1$ from the Elution buffer was added, centrifuged at $8000 \mathrm{rpm} / 1 \mathrm{~min}$. Then the column was discarded. The filtrate was put in clean tube containing the pure genomic DNA.

3. Amplification reaction of Arcobacter species (Wesley et al., 1995):

PCR reactions were performed in a reaction mixture (50 $\mu 1$ volume) containing $2 \mu \mathrm{l}$ of lysed bacteria, $5 \mu 1$ of Gibco BRL 10U PCR bujer, 1.5 U of Taq DNA polymerase (Gibco), $0.2 \mathrm{mmol} 131$ of each deoxyribonucleotide triphosphate, $1.3 \mathrm{mmol} 131$ $\mathrm{MgCl} 2,5 \mathrm{Wl}$ of loading bujer (4 mM cresol red, $60 \%$ sucrose) and 50 pmol of the primers ARCO, BUTZ, CRY1, CRY2, and 25 pmol of primer SKIR. 
Accurately, PCR involved 32 cycles of denaturation $\left(94^{\circ} \mathrm{C}\right.$ for $\left.45 \mathrm{sec}\right)$, primer annealing $\left(61^{\circ} \mathrm{C}, 45 \mathrm{sec}\right)$ and chain extension $\left(72^{\circ} \mathrm{C}, 30 \mathrm{sec}\right)$. Amplified products were detected by electrophoresis in $1.5 \%$ agarose in 0.5 U Tris- borate, EDTA buffer at 100 volts for 40 min. The PCR products were electrophoresed in $1.5 \%$ of agarose gel electrophoresis stained with ethidium bromide and visualized on UV transilluminator.

\section{Antimicrobial susceptibilities of Arcobacter species:}

Three different species, Arcobacter cryaerophilus A. skirrowii and A. butzleri isolated in the present study were used. A total of 10 commercially available antibiotic disks (Oxoid Hampshire, UK) were employed. The antibiotics and their concentrations ( $\mu \mathrm{g} /$ disk) are shown in the Table (3). The diskdiffusion test was used for the determination of the antimicrobial susceptibility of the Arcobacter isolates as described by (Woods and Washington, 1995). Briefly, the isolates were grown aerobically at $30{ }^{\circ} \mathrm{C}$ for $48 \mathrm{~h}$. After cultivation, a suspension of each organism was made in physiological saline and the turbidity of each inoculum was adjusted to McFarland 0.5 . Bacteria from each suspension were inoculated onto blood agar that comprised $5 \%(\mathrm{v} / \mathrm{v})$ defibrinated sheep blood in blood agar base no. 2 (Oxoid CM271) using a sterile cotton-tipped swab. Thereafter, each antibiotic disk was placed onto the agar and the plates were kept at $4{ }^{\circ} \mathrm{C}$ for about $20 \mathrm{~min}$ in order to allow the antibiotics to diffuse into agar. Incubation of the plates took place aerobically at $30{ }^{\circ} \mathrm{C}$ for $48 \mathrm{~h}$ and the diameter of the inhibition zones was measured with calipers. The susceptibility patterns (resistance / sensitivity) of the strains were determined according to previously defined criteria (Woods and Washington, 1995).

\section{Determination The minimum inhibitory concentration (MIC) and minimum lethal concentration (MLC) of Sodium chloride (SC) and sodium acetate (SA) against Arcobacter spp.:}

Preparation of inoculums: (Elaine, 2005)

Genotyped strains of A. cryaerophilus A. skirrowii and $A$. butzleri isolated in the present study were stored at $-70^{\circ} \mathrm{C}$ in Meuller-Hinton broth supplemented with $20 \%$ glycerol. Before use, they were subcultured onto $5 \%$ bovine blood agar plates and incubated aerobically at $30{ }^{\circ} \mathrm{C}$ for $48 \mathrm{~h}$. Isolated colonies of each culture were individually inoculated into liquid growth media aerobically at $30{ }^{\circ} \mathrm{C}$ for $30 \mathrm{~h}$ (the target stationary-phase cells were obtained in this period). Suspensions turbidity was adjusted to match that of 2 McFarland standard to obtain a final concentration of $10^{7}$ cells $/ \mathrm{ml}$ of target Arcobacter spp.

The (MIC) and (MLC) of SC and SA were established using the broth dilution method, as described by Jayana et al. (2010).Two-fold serial dilution of SC and SA $(0.03 \%, 0.06 \%, 0.125 \%$, $0.5 \%, 1 \%, 2 \%, 4 \%$ and $8 \%, 16 \%$ and $24 \%(\mathrm{w} / \mathrm{v})$ were prepared separately using sterile Muller Hinton broth. Each tube was inoculated by $100 \mu \mathrm{L}$ from the $30 \mathrm{~h}$ age culture of target organism to obtain final bacterial concentration of approximately $1 \times 10^{7} \mathrm{CFU}$ $/ \mathrm{ml}$ broth. The tubes together with the control tube (an inoculated and non inoculated tubes contained broth only) were incubated aerobically at $30{ }^{\circ} \mathrm{C}$ for $72 \mathrm{~h}$. The lowest concentration of the antibacterial that inhibits growth of the organism as detected by lack of visible turbidity was designated the MIC. To determine the MLC, $100 \mu \mathrm{L}$ from each clear tube (no visible growth) was surface spread over the dry surface of Campylobacter blood-free agar (Oxoid, UK) after 24, 48 and 72 hours of incubation. In each case, the inoculated plates were incubated aerobically at $30{ }^{\circ} \mathrm{C}$ for $72 \mathrm{~h}$. Growth of the microorganism from any incubation period at a particular concentration indicated that the lethal concentration was not achieved. MLC was defined as the lowest concentration of tested substances that killed the test organism (No growth or survival at the given concentration within $72 \mathrm{~h}$ ). The mean MIC and MLC was recorded from triple readings in each test.

Behaviar of Arcobacter butzelri in presence of both sodium chloride and sodium acetate in growth medium: (Phillips, 1999)

Sodium chloride (SC) at $3 \%$ was combined with (SA) at five levels separately. G1 (3\% SC and $0.01 \%$ SA), G2 (3\% SC and $0.02 \% \mathrm{SA}), \mathrm{G} 3$ (3\% Sc and $0.03 \%$ SA), G4 (3\% SC and 0.04\% SA) and G5 (3\% SC and $0.05 \%$ SA) were prepared using sterile MullerHenton broth. Each tube was inoculated by $100 \mu \mathrm{L}$ from the $30 \mathrm{~h}$ age culture of $A$. butzleri to obtain final bacterial concentration approximately of $1 \times 10^{7} \mathrm{CFU}$ $/ \mathrm{ml}$ broth. The tubes together with the control tubes (an inoculated and non inoculated tubes contained broth only) were incubated aerobically at $30{ }^{\circ} \mathrm{C}$ for $72 \mathrm{~h}$. One $-\mathrm{ml}$ samples from each culture were serially diluted using sterile $0.1 \%$ peptone water. Appropriate dilutions were surface spread over the dry surface of Campylobacter blood-free agar (Oxoid, UK) plates and incubated aerobically at $30{ }^{\circ} \mathrm{C}$ for $72 \mathrm{~h}$. The plates were counted and the counts were expressed as log 10 $\mathrm{CFU} / \mathrm{ml}$.

Behaviar of Arcobacter butzelri in presence of both sodium chloride and sodium acetate in minced beef model:

Preparation of minced beef and inoculation: (Elaine, 2005)

Fresh beef from the thigh area (Musculus Semimembranosus) were purchased from the local meat retailer for each replicate. The meat were assessed for Arcobacter then were manually cut into trimmings and aseptically coarse grounded with a meat grinder with a $5 \mathrm{~mm}$ hole diameter strainer and stored at $\left(-18^{\circ} \mathrm{C}\right)$ for $24 \mathrm{~h}$ in order to eliminate 
background microflora that were likely to confound the results. As needed, portions of ground meat were thawed overnight at $4^{\circ} \mathrm{C}$, mixed for homogeneity and divided into two groups. To group A (treated group) SC at level of $3 \%$ and SA at $0.05 \%$ were added and aseptically mixed. Group B was (the control). Individual $25 \mathrm{~g}$ portions of both groups were aseptically weighed and transformed manually into minced meat finger. Calculated count of $10^{7} \mathrm{CFU} / \mathrm{g}$ (one $\mathrm{ml}$ ) portion of $A$. butzleri suspensions prepared as motioned previously were injected into the center of each finger using a sterile syringe. Inoculated fingers were inserted through a sterile stomacher sac and placed $4{ }^{\circ} \mathrm{C}$.

Counting of survivors: (Phillips, 1999)
Samples were withdrawn at selected intervals $(0,3,6$, 12 and 24h).Treated and control samples were analyzed for Arcobacter count. Approxmately, 225 $\mathrm{ml}$ of peptone water was add to each sample, and the sample was stomached (Tekmar model 400, Tekmar, Cincinnati, $\mathrm{OH}$ ) for $2 \mathrm{~min}$ at normal speed. Aliquots of appropriate dilutions were plated on 5\% bovine blood agar plates with CAT supplement, which were incubated aerobically at $30{ }^{\circ} \mathrm{C}$ for $72 \mathrm{~h}$. Colonies were counted and converted to $\log 10 \mathrm{CFU} / \mathrm{g}$ counts. All experiments were repeated 3 times and the packaged SPSS program for windows version 12.0.1 was used for statistical analysis according to (SPSS, 2007). Data were expressed as mean \pm standard error (SE). Differences between groups were determined by means of a Student " $t$ "-test. Significance level was set at $P<0.05$.

\section{RESULTS}

Table 2: Prevalence of Arcobacter spp. in meat, minced meat and fish.

\begin{tabular}{|c|c|c|c|c|c|c|c|c|c|c|c|}
\hline \multirow{3}{*}{$\begin{array}{l}\text { Types of } \\
\text { samples }\end{array}$} & \multirow{3}{*}{$\begin{array}{c}\text { No. of } \\
\text { examined } \\
\text { samples }\end{array}$} & \multicolumn{4}{|c|}{ Arcobacter spp. } & \multicolumn{6}{|c|}{ Genotyping confirmation } \\
\hline & & \multicolumn{2}{|c|}{ Biochemical } & \multicolumn{2}{|c|}{ PCR } & \multicolumn{2}{|c|}{$\begin{array}{l}\text { Arcobacter } \\
\text { cryaerophilus }\end{array}$} & \multicolumn{2}{|c|}{$\begin{array}{l}\text { Arcobacter } \\
\text { skirrowii }\end{array}$} & \multicolumn{2}{|c|}{$\begin{array}{c}\text { Arcobacter } \\
\text { butzleri }\end{array}$} \\
\hline & & $\begin{array}{l}\text { No. } \\
+ \text { +ve }\end{array}$ & $\%$ & $\begin{array}{l}\text { No. } \\
\text { +ve }\end{array}$ & $\%$ & No. +ve & $\%$ & No. +ve & $\%$ & $\begin{array}{l}\text { No. } \\
+\mathrm{ve}\end{array}$ & $\%$ \\
\hline Fresh beef & 25 & 13 & 52 & 5 & 20 & 1 & 4 & 2 & 8 & 2 & 8 \\
\hline $\begin{array}{l}\text { Fresh } \\
\text { minced } \\
\text { beef }\end{array}$ & 25 & 12 & 48 & 2 & 8 & 0 & 0 & 1 & 4 & 1 & 4 \\
\hline Fish & 25 & 10 & 40 & 4 & 16 & 1 & 4 & 2 & 8 & 1 & 4 \\
\hline Total & 75 & 35 & 47 & 11 & 15 & 2 & 3 & 5 & 7 & 4 & 5 \\
\hline
\end{tabular}

Table 3: Susceptibility of Arcobacter spp. to antimicrobial agents.

\begin{tabular}{cccc}
\hline Antimicrobial agent & $\begin{array}{c}\text { Arcobacter } \\
\text { cryaerophilus }\end{array}$ & Arcobacter skirrowii & Arcobacter butzleri \\
\hline Gentamycin 10 & $\mathrm{S}$ & $\mathrm{S}$ & $\mathrm{S}$ \\
\hline Ciprofloxacillin 5 & $\mathrm{R}$ & $\mathrm{S}$ & $\mathrm{S}$ \\
\hline Neomycin 30 & $\mathrm{S}$ & $\mathrm{S}$ & $\mathrm{I}$ \\
\hline Lincomycin 2 & $\mathrm{R}$ & $\mathrm{R}$ & $\mathrm{R}$ \\
\hline Vancomycin 30 & $\mathrm{R}$ & $\mathrm{R}$ & $\mathrm{R}$ \\
\hline Cloxacillin 1 & $\mathrm{R}$ & $\mathrm{R}$ & $\mathrm{R}$ \\
\hline Tetracycline 30 & $\mathrm{R}$ & $\mathrm{R}$ & $\mathrm{R}$ \\
\hline Cephradine 30 & $\mathrm{R}$ & $\mathrm{R}$ & $\mathrm{R}$ \\
\hline Novobiocin 30 & $\mathrm{R}$ & $\mathrm{R}$ & $\mathrm{R}$ \\
\hline Oxacillin 1 & $\mathrm{R}$ & $\mathrm{R}$ & $\mathrm{R}$ \\
\hline Resistance $\%$ & $80 \%$ & $70 \%$ & $70 \%$ \\
\hline S: susceptible R: resistance & $\mathrm{I}:$ intermediate & &
\end{tabular}


$\underline{\text { Assiut Vet. Med. J. Vol. } 61 \text { No. } 146 \text { July } 2015}$

Table 4: MIC and MLC of sodium chloride and of sodium acetate against Arcobacter spp.

\begin{tabular}{lcc}
\hline Parameters & Sodium chloride $\%$ & Sodium acetate $\%$ \\
\hline MIC & 8 & 4 \\
\hline MLC & 9 & 6 \\
\hline
\end{tabular}

Fig. 1: Combined effect of sodium chloride 3\% and different concentration of sodium acetate on Arcobacter butzleri in the growth medium.

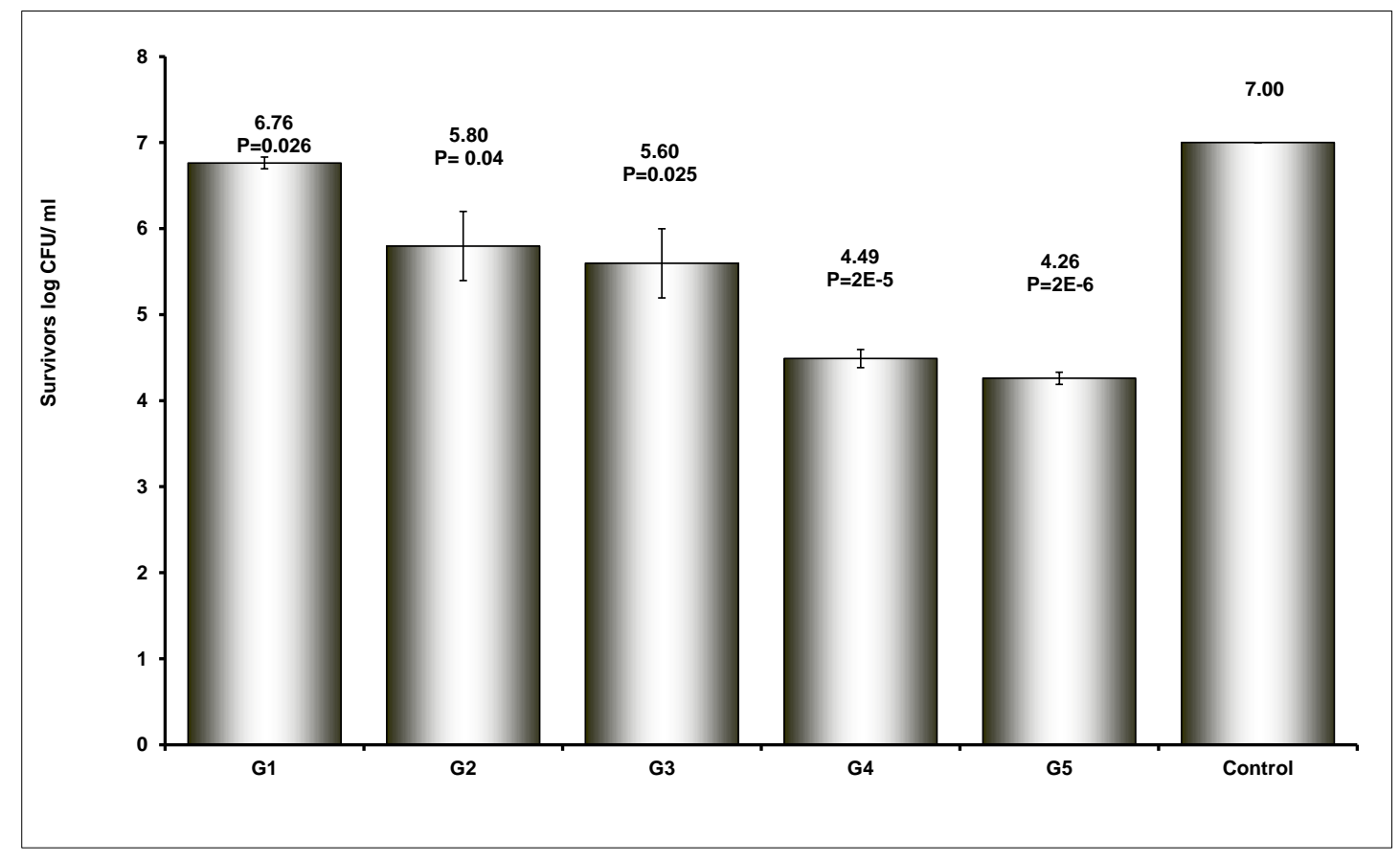

Fig. 2: Combined effect of 3\% sodium chloride and $0.05 \%$ of sodium acetate on Arcobacter butzleri in refrigerated minced meat




Fig. 3: Agarose gel electrophoresis of multiplex PCR for characterization of A. cryaerophilus, A. butzleri and A. skirrowii.

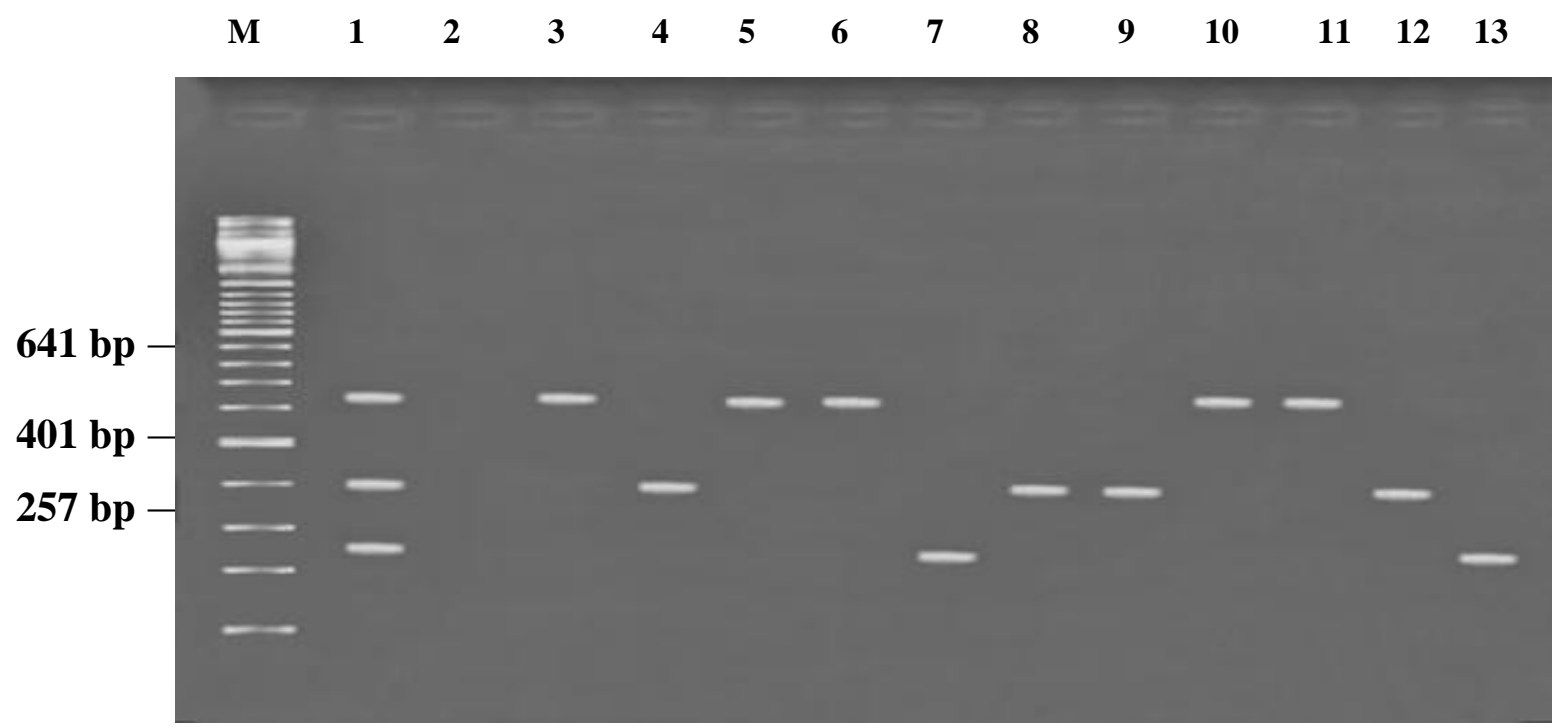

Lane M: 100 bp ladder as molecular size DNA marker.

Lane 1: Control positive for A. cryaerophilus, A. butzleri and A. skirrowii.

Lane 2: Control negative for A. cryaerophilus, A. butzleri and A. skirrowii.

Lanes 7 \& 13: Positive A. cryaerophilus strains for 23S rDNA (257 bp).

Lanes 4, 8, 9 \& 12: Positive A. butzleri strains for 16S rDNA (401 bp).

Lanes 3, 5, 6, 10 \& 11: Positive A. skirrowii strains for 16S rDNA (641 bp).

\section{DISCUSSION}

Arcobacter spp. are considered 'emerging' pathogens based on the characteristics they share with Campylobacters, potentially extending from morphological similarities to infectious capabilities and transmission routes, (Wesley, 1996). Miller et al. (1998) discussed characteristics of A. butzleri that contribute to its consideration as an'emerging' pathogen, and suggested that factors involved in the emergence of Escherichia coli O157:H7 may be shared by A. butzleri.

In this study, only $47 \%$ and $15 \%$ of raw food samples were found to be contaminated with Arcobacter spp. by phenotyping (PT) and genotyping (GT) methods, respectively (Table 2 ). Fresh beef samples were the most contaminated within surveyed raw foods in retail shops. By (PT), 52 \% contained Arcobacter spp. while (GT) revealed their presence in $20 \%$ of samples only. Of the fresh minced beef samples, $48 \%$ and $8 \%$ contained Arcobacter spp. by (PT) and (GT), respectively. Also fish acts as a source of Arcobacr spp in this study. As shown in (Table 2), the (PT) procedures detected Arcobacr spp in $40 \%$ of samples. By (GT), $16 \%$ were proved to harbor Arcobacr spp. Arcobacters are biochemically inert and have fastidious growth requirements, which make their speciation problematic using standard phenotypic procedures, (On et al., 1995). Vytrasova et al. (2003) stated that biochemical tests alone are not adequate to confirm Arcobacter spp., unless they are followed by
PCR assay. The reasons were explained by Milesi, (2010) who mentioned that differentiating of Arcobacter spp. by using phenotypic tests might give erroneous results because of the shortage of clear-cut differentiating tests, a phenomenon which has also been observed in the closely related genus Campylobacter.

However, the PCR assay using primers specific to each Arcobacr spp (Houf et al., 2000), which was employed in the present study, has shortened significantly the time required for the identification of Arcobacters at the species level and also removed the possibility of false positive results due to Campylobacters. The findings commented before explained the low prevalence of Arcobacr spp. using (GT) comparing with (PT) in the present study.

In other studies, detection by molecular methods has shown an incidence of Arcobacr spp ranging between 1.4\% (Collado et al., 2009) and $55 \%$ (Vytrasova et al., 2003). A study included detection using culturing and molecular method in parallel reported that $0.7 \%$ of the samples positive by culturing, and $1.4 \%$ by molecular detection (Collado et al., 2009).

The isolation rate of Arcobacters from meat samples was higher than, 2.2\% (Kabeya et al., 2003) and lower than $55.6 \%$ (Vytrasova et al., 2003), 22\% (Rivas et al., 2004), 34\% (Scullion et al., 2006) and $37 \%$ (Aydin et al., 2007) which were reported for fresh beef samples. Various factors such as 
differences in hygienic conditions in each abattoir as well as differences in the sensitivity of sampling and isolation methods used in these studies may have contributed to these variation.

Regarding minced beef samples, our findings (8\%) were within the range of $4-10 \%$ recorded by (Rohder et al., 2007; Nieva-Echevarria et al., 2013), respectively and lower than that $(90.9 \%)$ of (Abd El Rahman et al., 2012).

From (Table 2), A. butzleri and A.skirrowii, predominated $A$. cryaerophilus in both fresh beef and fresh minced beef samples. A. cryaerophilus was not detected in minced beef. The predominance of $A$. butzleri in beef or minced beef was also recorded by (O” ngo". r et al., 2004). A. cryaerophilus were reported to be less frequent in meat samples including poultry meat, (Houf et al., 2001; Atabay et al., 2002; Kabeya et al., 2003). However, the isolation of Arcobacters from red meat samples, which were collected from retail markets, appears significant when the risk for human health was considered (O”ngo“" r et al., 2004).

Arcobacters in cattle have been associated with different syndromes such as mastitis, enteritis and reproduction disorders including abortion and recurrent breeding problems in the herd (Logan et al., 1982; Ho et al., 2006). However, none of those studies have shown an unequivocal relation between the presence of Arcobacters and those pathologies. Moreover, Arcobacters are frequently present in healthy cattle by which they may act as an unnoticed contamination risk during slaughter.

It is commonly assumed that enteric pathogens found on raw meat are mainly derived from faecal origin (Heuvelink et al., 2001). A. butzleri was the predominant species on all carcasses sampling sites, which corresponds with the species distribution in cattle prior to slaughter (O"ngo"r et al., 2004). Spreading of Arcobacters between animals may occur in the holding pen prior to slaughter or by the slaughter equipment. Also, crosscontamination between carcasses during slaughter was reported by Van Driessche and Houf (2007).

Arcobacter spp. were isolated from fish muscle, (Table 2). Forty percent and $16 \%$ of fish samples contained Arcobacter spp. using (PT) and (GT), respectively with $A$. skirrowii as the dominant species detectable in $8 \%$ of the samples. The prevalence of A. cryaerophilus and A.butzleri was parallel each (4 $\%)$. Patya et al. (2011) recorded the detection of Arcobacr spp. by 17.33 and $21.33 \%$ using culture and PCR techniques, respectively. Nonetheless, comparable prevalence was detectable in shellfish $(73.3 \%)$ and musscles $(41.1 \%)$ in northern Spain (Collado et al., 2009; Nieva-Echevarria et al., 2013).
Our data suggests that fish represents an important reservoir for Arcobacter spp. and confirm that genetic diversity of A. butzleri strains is also common among isolates originated from fish. The abundant presence of three Arcobacter species in red meat and fish suggests an important role of contaminated food in the transmission of these bacteria.

In the current study, a total of three isolates of various Arcobacter spp. including A. cryaerophilus, $A$. skirrowii, and $A$. butzleri that were isolated from meat and fish samples were tested for their susceptibilities to 10 antibiotics. The results are summarized in table 3. The three Arcobacter spp. tested were resistance to Lincomycin, Vancomycin, Cloxacillin, Cephradine, Novobiocin, Tetracycline and Oxacillin. A. cryaerophilus was the most resistance within tested Arcobacters. It was resistance to $80 \%$ of tested antibiotics. A. skirrowii and A. butzleri were parallel in their resistance, $70 \%$ each.

A. skirrowii was the most susceptible within Arcobacters. It showed susceptibility to Gentamycin, Ciprofloxacillin and Neomycin. A. butzleri showed only intermediate susceptibility to Neomycin while $A$. cryaerophilus was the only resistance to Ciprofloxacillin, (Table 3). Gentamycin was the most active antibiotics against the A. cryaerophilus, $A$. skirrowii and A. butzleri.

Lack of gold-standard sensitivity methods and break points of antibiotics has made the comparison of results of antibiotic resistance patterns more difficult. A. skirrowii was reported to be the most susceptible Arcobacter species, (Houf et al., 2001) which coordinate with our findings. By using E-test method, Otth et al. (2004) reported that all Arcobacter tested isolates were sensitive to Gentamycin. Unver et al. (2012) found that A. cryaerophilus, A. skirrowii and A. butzleri were resistance to Vancomycin and Cloxacillin.

Different results were reported in a recent study that evaluated the resistance to antibiotics of several strains recovered from cattle, beef, milk and water using a disk diffusion method. Only $6.5 \%$ of the tested strains showed resistance to Tetracycline, $21.7 \%$ to Ciprofloxacine and $26.1 \%$ to Gentamycin, (Shah et al., 2011). When considering the results obtained for clinical strains using different methods (Kayman et al., 2012 and Mandisodza et al., 2012), reported that most isolates showed susceptibilities to Ciprofloxacin, Gentamycin and Tetracycline.

In the present study, A. cryaerophilus, A. skirrowii, and $A$. butzleri isolates were resistant to six or more antibiotics (multi drug resistant). Multi drug resistance (MDR) in Arcobacter spp. has also reported by some other researchers. Son et al. (2010) reported $71.8 \%$ of $A$. butzleri were MDR, whereas 
Vandenberg et al. (2006) recorded $6.2 \%$ of A. butzleri isolates showing MDR resistance to Ampicillin, Erythromycin and Nnalidixic acid.

The increased level of drug resistance, as encountered in this study, is important in terms of both animal and public health. The more popular opinion is that the use of antibiotics, especially in food animals, will lead to the development of antibiotic resistance which in turn can be disseminated through the environment and led to resistant infections in humans, (Angulo, 2003). Because of the similarity in antibiotic use between animals and humans, a serious concern is that once resistance develops in animals it will soon affect humans, (CDC, 2006).

The incidence of antibiotic susceptibility in Arcobacters varied among species, which suggests that suitable antibiotic(s) should be selected for the treatment of infectious disease(s) and/or when developing selective media for the isolation of a wide range of Arcobacters. Lincomycin, Vancomycin, Tetracycline, Cloxacillin, Cephradine, Novobiocin and Oxacillin, could not be considered as drugs of choice for treatment of Arcobacter borne gastrointestinal disease. Contrary to this, Gentamycin would be the drugs of choice and Neomycin as alternative.

To study the growth and survival characteristics of Arcobacter spp. with a view to identify intervention techniques that would reduce their presence in food products and environments with which they have been associated, the behavior of Arcobacter spp. against SC and SA alone or mixed was studied. The three tested Arcobacters (A. butzleri and $A$. skirrowii, and A. cryaerophilus) respond to SC and SA environment in the same way. Arcobacters couldn't tolerate $9 \%$ salt (SC) concentration in growth medium, (Table, 4). The MIC of the three Arcobacter spp. tested was $8 \%$. In a related study, Elaine, (2005) found that Arcobacter spp. could grow at SC levels up to $5 \%$ depending on the species and strain of concern. The growth in nearly similar concentrations of (SC) was recorded for other foodborne pathogens. McClure et al. (1989) observed growth of $L$. monocytogenes within 72 hours in $10 \% \mathrm{SC}$ at $25^{\circ} \mathrm{C}$.

Sodium acetate showed bactericidal effect against Arcobacters. When tested against $A$. butzleri and $A$. skirrowii, and A. cryaerophilus, the MIC of SA was $6 \%$ while the MLC was 9\%, (Table, 4). Sodium salts of the low molecular weight organic acids, such as acetic lactic and citric have been used to control microbial growth, improve sensory attributes and extend the shelf life of various food systems. In addition to their effect on food spoilage bacteria, these organic salts were shown to possess antibacterial activities against foodborne pathogens (Blom et al., 1997 and Ehsani et al., 2013). One advantage of SA is that its antibacterial action less affected by the $\mathrm{pH}$ of the medium particularly at $\mathrm{pH}$ 5.0-6.5. Against Yersinia enterocolitica, SA resulted in MIC of $47.80 \mathrm{mg} / \mathrm{ml}$ at $\mathrm{pH} 4.5$ while MIC $(52.50 \mathrm{mg} / \mathrm{ml})$ at $\mathrm{pH}$ range from 5.0-6.5, (Nanasombat and Chooprang, 2009). Sodium acetate has also been known to exhibit antilisterial effect, (FDA, 2000).

In food system cold storage alone was not sufficient to reduce Arcobacter risk to an acceptable level. Cold storage was reported to reduce viability of Arcobacter. Freezing reduces the number of Arcobacter by $1-2 \operatorname{logs}$, but freezing alone is not sufficient to reduce risk to an acceptable level, (Hansen and Olsen 2007). Additional steps are needed to insure that the meat and meat products are safe for the consumers. All of these additional steps are combined with meat curing or brining. In the last few years different combinations of common salt and salts of organic acids (acetic, lactic, tartaric or citric) have been made that can be applied to the meat during the curing of brining process, or directly (without curing or brining).

In the present study, the application of SC or SA against Arcobacter spp. in meat system was faced with two problems. First, the both MIC and MLC of $\mathrm{SA}$ were higher than the limit $(5000 \mathrm{mg} / \mathrm{kg})$ recommended for use in meat, (Queensland Government, 2013). The $2^{\text {nd }}$ is that new trends in minced meat technology works in the direction of SC reduction. To overcome these problems the combined effect of low concentrations of both antimicrobials were tested against A. butzleri in growth medium.

From the results shown in (Fig. 1), the reduction in $A$. butzleri counts due to combined effect of SC and SA ranged from $0.2-2.7 \log \mathrm{CFU} / \mathrm{ml}$ after $24 \mathrm{~h}$ incubation at $30{ }^{\circ} \mathrm{C}$ compared with the control (initial count). The highest reduction level in A. butzleri cells was related to combination of $3 \% \mathrm{SC}$ plus $0.05 \% \mathrm{SA}$ (G5). There were significant differences $(\mathrm{P}<0$.05) between treatments (G1 - G5) compared with control, (Fig.1). Despite the various studies showed the use of SC, singly agonist Arcobacter spp. in broth, there is scarce of literature concerned with the combination effects with SA.

As the formula $(3 \% \mathrm{SC}+0.05 \% \mathrm{SA})$ was the most effective treatment against $A$. butzleri in growth medium, it was chosen for addition in minced beef system. The antibacterial mixture needed $12 \mathrm{~h}$ to produce $1 \log$ reduction in the initial $A$. butzleri count and the reduction was proximate at $24 \mathrm{~h}$ period, (Fig. $2)$. By the end of 24 of refrigeration storage, the $A$. butzleri count was $5.48 \mathrm{CFU} / \mathrm{g}$ in antimicrobial mixture treated samples, it reached $7.19 \mathrm{CFU} / \mathrm{g}$ in control samples. The difference in A. butzleri count between treatment and control samples was significant $(\mathrm{P}<0.05)$ as shown in (Fig. 2). 
Sodium salt is GMP (Good Manufacturing Practice) listed with meats, (DJC, 2009). Sodium salt of chloride has a rich history of use in ensuring meat safety before refrigeration, (American Meat Institute, 2010). Besides the antimicrobial properties, SC increases the bind, firmness, cooked yield and taste, in minced meat, (Madril and Sofos, 1985). The use of $\mathrm{SC}$ in meat processing at level of $3 \%$ was reported. Anbalagan et al. (2013) found that 3\% SC treated group was recorded the very low bacterial load in all meats (Chicken, Mutton and Beef) compared to other treated groups. It was found that the pro-oxidant activity of SC accelerates the development of lipid oxidation in refrigerated meats (Lee et al., 1997) but acetates can antagonize that effect. It had been reported that acetates have antioxidant effects and they prevent the occurrence of the undesirable changes in the sensory properties of the products, such as colour, taste, odour, etc., (Gökalp et al., 2004).

The combination of sodium chloride with other antimicrobial agents may have an impact on the overall inhibitory effect. Sallam (2007) reported 1.2 $\log$ reductions in the total bacterial count by application of SA, and SC combination on refrigerated sliced salmon. Casey and Condon (2002) found that $\mathrm{SC}$ reduced the inhibitory effect of acid $\mathrm{pH}$ on the growth of Escherichia coli O157: H7. Tan and Shelef (2002) reported that a combination of SC and sodium lactate was more effective than lactates alone in delaying the onset of meat spoilage and its effects on its color and bacterial counts. Sallam and Samejima (2004) reported the use of sodium chloride in combination with sodium lactate reduced the microbial growth, maintained the chemical quality and extended the shelf life of ground beef during refrigerated storage.

Sodium acetate has proven useful for controlling pathogens in a variety of meat and poultry products. An uncured turkey product was able to remain free of the Clostridium botulinum neurotoxin for over 18 days at $28^{\circ} \mathrm{C}$ when treated with $6 \%$ sodium acetate, (Miller et al., 1992). The use of sodium acetate and diacetate as flavor enhancers should be limited to less than $0.25 \%$ by weight of total formulation, (USDAFSIS, 2000).

Recent studies have shown the effects of sodium acetate combined with other antimicrobial agents at inhibiting L. monocytogenes. Individually, 2.5\% sodium lactate and $0.25 \%$ sodium acetate both strongly inhibit the growth of L. monocytogenes, (Blom et al., 1997). However, in the same study, a combination of $2.5 \%$ sodium lactate, $0.25 \%$ sodium acetate, and $2.75 \%$ salt completely inhibited the organism, (Blom et al., 1997).
Survival of pathogens in the environment and in food products is governed by a complex array of factors. Several of these factors are inherent in the genotypic composition of the genus and are reflected in the ability to adapt to adverse conditions commonly encountered in their reservoir area (soil, water, animals) or in the environment into which they have been artificially introduced (foods, susceptible unnatural host animals, etc.). These adaptive mechanisms are often transferable between genera, or more commonly species, conferring 'potential pathogen' status on 'newly emerging' microorganisms, (Elaine, 2005).

In our study, the antimicrobial combination in food system was not as effective as in broth when used at the same concentration. This was in agreement with Drosinos et al. (2006) who indicated that addition of MIX 1 (lactic acid, sodium acetate and potassium sorbate) and MIX 2 (potassium lactate and potassium acetate) prevented the lactic acid bacteria in growth medium, but not in meat product. Moreover, meat composition including protein and fat and some components that are cryoprotectants may protect microorganisms from destruction. It has been suggested that Arcobacter spp. can survive in food because they can tolerate high sodium chloride concentrations, desiccation, can grow at lower refrigeration temperatures and have the ability to attach to various types of surfaces (Collado and Figueras, 2011).

In conclusion, this study revealed that the fresh meat and fish from the retail market are important source of Arcobacters that may play role in the contamination of the environment and human food chain. Further efforts are needed to investigate cases with diarrheal illness to elucidate the role of $A$. butzleri in veterinary public health in this geographical area. Such epidemiologic data is important for preventive strategies and control of diarrheal diseases, especially in remote areas where populations share food sources available in only a few local markets. Gentamycin would be drugs of choice and Neomycin as alternative for treatment of Arcobacter borne gastrointestinal infection in this geographical area.

Using organic acid salt (SA) in combination with SC is capable of decreasing the number of viable cells of A. butzleri in fresh minced beef under refrigerated storage, thereby enhancing microbiological safety of minced beef products. However, addition of organic acid salts at concentrations higher than the permissible limits is recommended is in order to eliminate the $A$. butzleri effectively. 


\section{REFERENCES}

Abd El Rahman, H.A.; Ahmad, A.M.; Mona, M. Abdelwahab and Salowa, M. Salem (2012): Arcobacter species as newly emerging foodborne pathogen in meat at Ismailia Governorate. SCVMJ, XVII (2): 21- 26.

American Meat Institute "AMI" (2010): Salt Use in Meat and Poultry Products. AMI Fact Sheet. January 2010. http://www.MeatAMI.com.

Anbalagan, M.; Ganesh Prabu, P.; Krishnaveni, R.E. and Manivannan, S. (2013): Effect of Sodium Chloride $(\mathrm{NaCl})$ on the Bacterial Load in Chicken, Mutton and Beef Meat Samples in Relation to Meat Spoilage. International Journal of Research in Zoology 4(1): 1-5.

Angulo, L. (2003): Public health consequences of use of antimicrobial agents in agriculture. In: Knobler, S.L., Lemon, S.M., Najafi, M., Burroughs, T. (Eds.), Forum on Emerging Infections: The Resistance Phenomenon in Microbes and Infectious Disease Vectors. Implications for Human.Centers for Disease Control and Prevention. 2005. http://www. cdc.gov/narms/(viewed Nov. 2005).

Atabay, H.I.; Bang, D.D.; Aydin, F.; Erdogan, H.M. and Madsen, M. (2002): Discrimination of Arcobacter butzleri isolates by polymerase chain reaction-mediated DNA fingerprinting. Letters of Applied Microbiology 35, 141-145.

Aydin, F.; Gumussoy, K.S.; Atabay, H.I.; Ica, T. and Abay, S. (2007): Prevalence and distribution of Arcobacter species in various sources in Turkey and molecular analysis of isolated strains by ERIC-PCR. J. Appl Microbiol. 103: 27-35.

Blom, H.; Nerbrink, E.; Dainty, R.; Hagtvedt, T.; Borch, E.; Nissen, H. and Nesbakken, T. (1997): Addition of $2.5 \%$ lactate and $0.25 \%$ acetate controls growth of Listeria monocytogenes in vacuum-packed, sensoryacceptable servelat sausage and cooked ham stored at $4^{\circ} \mathrm{C}$. Int. J. Food Microbiol. 38:71-76.

Casey, P.G. and Condon, S. (2002): Sodium chloride decreases the bactericidal effect of acid $\mathrm{pH}$ on Escherichia coli O157: H7. Int. J. Food Microbiology, 76: 199-206.

"CDC" Centers for Disease Control and Prevention (2006): Preliminary Food Net data on the incidence of infection with pathogens transmitted commonly through food -10 states, United States 2005. MMWR Morb. Mortal Wkly Rep; 55: 392-5.

Collado, L.; Guarro, J. and Figueras, M.J. (2009): Prevalence of Arcobacter in meat and shellfish. J. Food Prot. 72: 1102-1106.

Collado, L. and Figueras, M.J. (2011): Taxonomy, epidemiology and clinical relevance of the genus Arcobacter. Clin. Microbiol. Rev., 24: 174-192.
Dave, D. and Ghaly, A.E. (2011): Meat spoilage mechanisms and preservation techniques: A critical review. American Journal of Agricultural and Biological Sciences 6 (4): 486-510

DJC "Department of Justice Canada" (2009): Food and Drug Act, Department of Justice Canada. http://laws.justice.gc.ca/en/showtdm/cr/C.R.C.c.870.

Dragoev, S. (2004): Development of technology in the industry for temperature had on good sensory characteristics of meat cuts that meat and fish. Academic Edition UFT Plovdiv, 259-263.

Drosinos, E.H.; Mataragas, M.; Kampani, A.; Kritikos, D. and Metaxopoulos, I. (2006): Inhibitory effect of organic acid salts on spoilage flora in culture medium and cured cooked meat products under commercial manufacturing conditions. Meat Sci. 73: 75-81.

Ehsani, A.; Jasour, M.S.; Hashemi, M.; Mehryar, L. and Khodayari, M. (2013): Zataria multiflora Boiss essential oil and sodium acetate: how they affect shelf life of vacuum-packaged trout burgers International Journal of Food Science and Technology (1-8) online version doi:10.1111/ijfs. 12400 .

Elaine, M. D'Sa. (2005): Effect of $\mathrm{pH}, \mathrm{NaCl}$ Content, and Temperature on Growth and Survival Arcobacter spp. Journal of Food Protection, 8, 1: 18-25.

FDA "Food and Drug Administration", U.S. (2000): Food additives for use in meat and poultry products: sodium diacetate, sodium acetate, sodium lactate, and potassium lactate. Fed. Regist. 65:13, 3121-3123.

Gökalp, Y.G.; Kaya, M. and Zorba, Ö. (2004): Et urunleri isleme mühendisligi (besinci baski). Atatürk Universitesi Ziraat Fakültesi Ofset Tesisi, Erzurum.

Hansen, F. and Olsen, K.E.P. (2007): Arcobacter an emerging food borne pathogen. NMKL Technical Report No. 2, Nordic Committee on Food Analysis.www.nmkl.org.

Heuvelink, A.E.; Roessink, G.L.; Bosboom, K. and De Boer, E. (2001): Zero-tolerance for faecal contamination of carcasses as a tool in the control of O157 VTEC infections. Int J Food Microbiol 66: 13-20.

Ho, H.T.K.; Lipman, L.J.A. and Gaastra, W. (2006): Arcobacter, what is known and unknown about a potential foodborne zoonotic agent!. Vet Microbiol 115: 1-13.

Houf, K.; De Zutter, L.; Verbeke, B.; Van Hoof, J. and Vandamme, P. (2003): Molecular characterization of Arcobacter isolates collected in a poultry slaughterhouse. Food Protection 66: 69-364.

Houf, K.; Devriese, A.L.; Dezutte, L.; Van Hoof, J.V. and Vandamme, P. (2001): Susceptibility 
of Arcobacter butzleri, Arcobacter cryaerophilus, and Arcobacter skirrowii to Antimicrobial Agents Used in Selective Media. J. Clin Microbiol. 39(4): 1654-1656.

Houf, K.; De Zutter, L.; Van Hoof, J. and Vandamme, $P$. (2002): Assessment of the genetic diversity among Arcobacters isolated from poultry products by using two PCR-based typing methods. Applied and Environmental Microbiology 68: 2172-2178.

Houf, K.; Tutenel, A.; De Zutter, L.; Van Hoof, J. and Vandamme, P. (2000): Development of a multiplex PCR assay for the simultaneous detection and identification of Arcobacter butzleri, Arcobacter cryaerophilus and Arcobacter skirrowii. FEMS Microbiology Letters 193: 89-94.

Jayana, L.; Prasai, T.; Singh, A. and Yami, K.D. (2010): Study of antimicrobial activity of lime juice against Vibrio cholerae. Scientific World, $8,(8)$ 44-46.

Kabeya, H.; Kobayashi, Y.; Maruyama, S. and Mikami, T. (2003): One step Polymerase chain reaction-based typing of Arcobacter species. Int. J. Food Microbiol., 81: 163-168.

Kayman, T. (2012): Arcobacter Cinsi: Genel Özellikleri, Epidemiyoloji ve Laboratuvar Tanıs1. Türk Mikrobiyol Cem Derg 42(2): 43-50.

Kayman, T.; Abay, S.; Hizlisoy, H.; Atabay, H.I.; Diker, K.S. and Aydin, F. (2012): Emerging pathogen Arcobacter spp. in acute gastroenteritis: molecular identification, antibiotic susceptibilities and genotyping of the isolated arcobacters. J. Med. Microbiol. 61: 1439-44.

Lee, S.K.; Mei, L. and Decker, E.A. (1997): Influence of sodium chloride on antioxidant enzyme activity and lipid oxidation in frozen ground pork. Meat Science. 46: 349-355.

Lee, S.; Decker, E.A. and Faustman, C. (2005): The effects of antioxidant combinations on color and lipid oxidation in $n-3$ oil fortified ground beef patties. Meat Science, 70(4): 683-689.

Logan, E.F.; Neill, S.D. and Mackie, D.P. (1982): Mastitis in dairy cows associated with an aerotolerant Campylobacter. Vet. Rec. 110: 229-230.

Madril, M.T. and Sofos, J.N. (1985): Antimicrobial and functional effects of six polyphosphates in reduced sodium chloride comminuted meat products. Lebensmittel- Wissenschaft- und Technologie, 18(5): 316-322.

Mandisodza, O.; Burrows, E. and Nulsen, M. (2012): Arcobacter species in diarrhoeal faeces from humans in New Zealand. $\mathrm{N} Z$ Z Med. J. 125: 40-46.

McClure, P.J.; Roberts, T.A. and Oguru, P.O. (1989): Comparison of the effects of sodium chloride, $\mathrm{pH}$, and temperature on the growth of Listeria monocytogenes on gradient plates and in liquid medium. Lett. Appl. Microbiol., 9: 95-99.

Milesi, S. (2010): Emerging pathogen Arcobacter spp. in food of animal origin. Doctoral Program in Animal Nutrition and Food Safety, Graduate School of Veterinary Science For Animal Health And Food Safety ersità degli Studi di Milano.

Miller, A.J.; Call, J.E. and Whiting, R.C. (1992): Comparison of organic acid salts for Clostridium botulinum control in an uncured turkey product. J. Food Prot. 56: 958-962.

Miller, A.J.; Smith, J.L. and Buchanan, R.L. (1998): Factors affecting the emergence of new pathogens and research strategies leading to their control. J. Food Saf. 18:243-263

Nanasombat, S. and Chooprang, L. (2009): Control of Pathogenic Bacteria in Raw Pork using Organic Acid Salts in Combination with Freezing and Thawing. Kasetsart J. (Nat. Sci.) 43: 576-583.

Nieva-Echevarria, B.; Martinez-Malaxetxebarria, I.; Girbau, C.; Alonso, $R$. and FernandezAstorga, A. (2013): Prevalence and genetic diversity of Arcobacter in food products in the North of Spain. J. Food Prot. 76: 1447-1450.

Öngo r, H.; Cetinkaya, B.; Acik, M.N. and Atabay, H.I. (2004): Investigation of arcobacters in meat and faecal samples of clinically healthy cattle in Turkey. Letters of Applied Microbiology 38: 344-39.

On, S.L.; Jensen, T.K.; Bille-Hansen, V.; Jorsal, S.E. and Vandamme, P. (2002): Prevalence and diversity of Arcobacter spp. isolated from the internal organs of spontaneous porcine abortions in Denmark. Veterinary Microbiology 85, 159-167.

On, S.L.; Stacey, A. and Smyth, J. (1995): Isolation of Arcobacter butzleri from a neonate with bacteremia. J. Infect., 31: 225-227.

Otth, L.; Wilson, T.M.; Cacino, R. and Fernandez, $H$. (2004): In vitro susceptibility of Arcobacter butzleri to six antimicrobial drugs. Arch. Med. Vet. XXXVI, 2,: 207-210.

Patya, A.; Rathore, R.S.; Mohan, H.V.; Dhama, K. and Kumar, A. (2011): Prevalence of Arcobacter spp. in Humans, Animals and Foods of Animal Origin Including Sea Food from India. Transboundary and Emerging Diseases .58, 5: 402-410.

Phillips, C.A. (1999): The effect of citric acid, lactic acid, sodium citrate and sodium lactate, alone and in combination with nisin on the growth of Arcobacter butzleri. Letters in Applied Microbiology 29: 424-428.

Queensland Government (2013): Food industry fact sheet, Appendix 2. Permitted additives for meat and meat products. www.health. qld.gov.au/foodsafety. 
Ray, B. (1996): $\quad$ Fundamental Food Microbiology.CRC Press, New York. 516

Rivas, L.; Fegan, N. and Vanderlinde, P. (2004): Isolation and characterization of Arcobacter butzleri from meat. Int J Food Microbiol 91, 31-41.

Rohder, A.; Kleer, J. and Hildebrandt, G. (2007): Using microbiological analysis by Johnson \& Murano and multiplex PCR by Harmon and Wesley for the identification of Arcobacter spp. in fresh poultry and beef sold in retail markets in Berlin. Arch Lebensmittel hygiene 58: $188-191$.

Sallam, K.I. (2007): Antimicrobial and antioxidant effects of sodium acetate, sodium lactate and sodium citrate in refrigerated sliced salmon. Food Contr., 18: 566-575.

Sallam, K.I. and Samejima, K. (2004): Microbiological and chemical quality of ground beef treated with sodium lactate and sodium chloride during refrigerated storage. Lebenson Wiss Technol., 37: 865-871.

Scullion, R.; Harrington, C.S. and Madden, R.H. (2006): Prevalence of Arcobacter spp. in raw milk and retail raw meats in Northern Ireland. J. Food Prot 69: 1986-1990.

Shah, A.H.; Saleha, A.A.; Zunita, Z. and Murugaiyah, M. (2011): Arcobacter an emerging threat to animals and animal origin food products. Trends Food Sci. Technol. 22: 225-236.

Shah, D.; Shringi, S.; Besser, T. and Call, D. (2009): Molecular detection of foodborne pathogens, Boca Raton: CRC Press, In Liu, D. (Ed). Taylor \& Francis group, Florida, USA, Pp. 369-389.

Son, I.M.D.; Engien, M.E.; Berrang, P.J.; Fedorka, C. and Harrison, M.A. (2010): Antimicrobial resistance of Arcobacter and Campylobacter from broiler carcasses. Int. J. Antimicrob. Agents, 29: 455-451.

SPSS (2007): Sample Power Statistic, SPSS, 12.01 Syntax Reference Guide for SPSS Base. SPSS Inc, 233South Wacker Drive, Chicago, IL.pp111-119.

Tan, W. and Shelef, L.A. (2002): Effects of sodium chloride and lactates on chemical and microbiological changes in refrigerated and frozen fresh ground pork. Meat Sci., 62: 27-32.

Tarrant, P.V. (1998): Some research advance and future priorities in research for the meat industry. Meat Science, 49 (Suppl 1), S1-S16.
Unver, A.; Ataby, H.I.; Şahin, M. and Eleb, Z. (2012): Antimicrobial susceptibilities of various Arcobacter species. Turk. J. Med. Sci. (2013) 43: 548-552.

USDA-FSIS "United States Department of Agriculture, Food Safety and Inspection Service" (2000): Food additives for use in meat and poultry products: sodium diacetate, sodium acetate, sodium lactate and potassium lactate: direct final rule. Federal Register 65: 31213123.

Van Driessche, E. and Houf, K. (2007): Characterization of the Arcobacter contamination on Belgian pork carcasses and raw retail pork. Int. J. Food Microbiol 118, 20-26

Vandenberg, O.; Dediste, A.; Houf, K.; Ibekwem, S.; Souayah, H.; Cadranel, S.; Douat, N. and Zissis, G. (2004): Arcobacter species in humans. Emerg Infect Dis 10: 1863-1867.

Vytrasova, J.; Pejchalova, M.; Harsova, K. and Binova, S. (2003): Isolation of Arcobacter butzleri and A. cryaerophilus in samples of meats and from meat processing plants by a culture technique and detection by PCR. Folia Microbiol., 48(2): 227-232.

Wesley, I.V. (1995): Oligonucleotide probes for the genus Arcobacter and for Arcobacter butzleri based on 16SrRNA sequence. J. Clin. Microbiol. 77: 1691-1698.

Wesley, I.V. (1996): Helicobacter and Arcobacter species: risks for foods and beverages. J. Food Prot. 59:1127-1132.

Wesley, I.; Schroeder, L.; Baetz, A.; Dewhirst, F. and Paster, B. (1995): Arcobacter species and Arcobacter butzleri species 16 rRNA-based DNA probes. J. Clin. Microbiol., 33: 1691-1698.

Woods, G.L. and Washington, J.A. (1995): Antibacterial susceptibility tests: dilution and disk diffusion methods. In: Murray, P.R.; Baron, E.J.O.; Pfaller, M.A.; Tenover, F.C. and Yolken, R.H., editors. Manual of Clinical Microbiology. Washington DC: ASM Press; p.1327-416.

Yan, J.J.; Ko, W.C.; Huang, A.H.; Chen, H.M.; Jin, Y.T. and Wu, J.J. (2000): Arcobacter butzleri bacteremia in a patient with liver cirrhosis. J. Formos. Med. Assoc., 99: 166-169. 


\section{ميكروبات الأركوباكتر ومخاطر ها في بعض اللحوم والاسماك مع مجابهتها بخلات وكلوريد الصوديوم \\ محمود عمار محمد عمار ، سبي حسن الهيتح

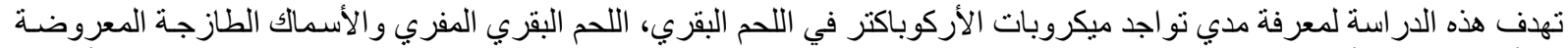

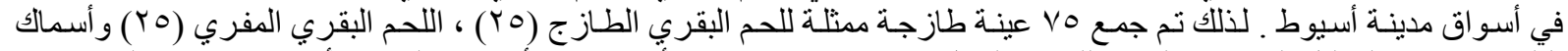

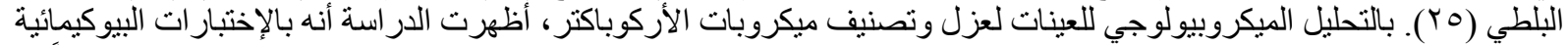

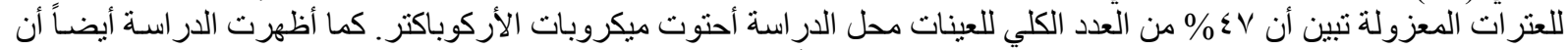

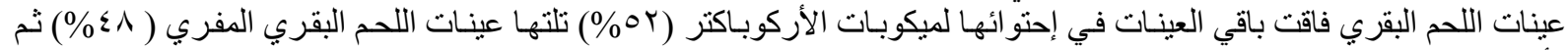

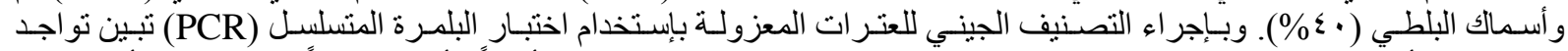

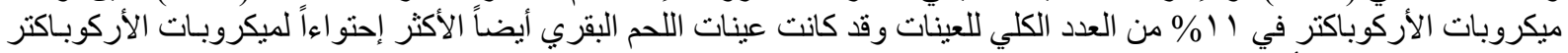

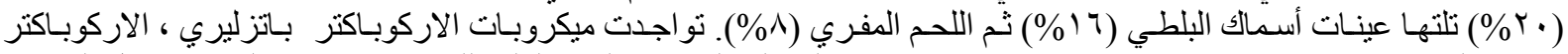

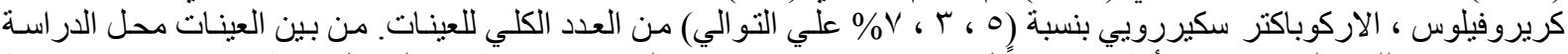

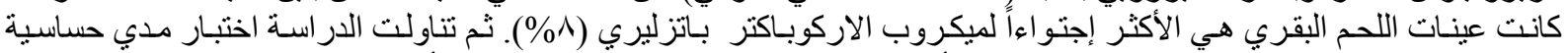

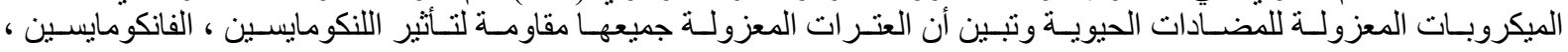

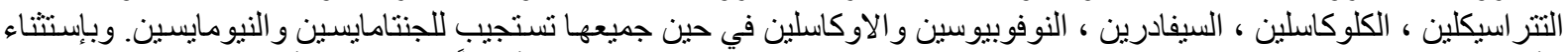

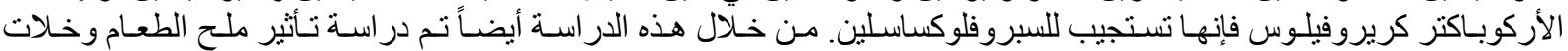

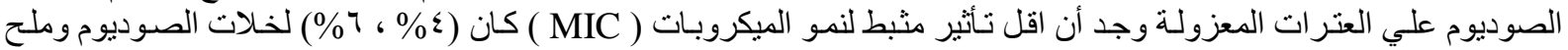

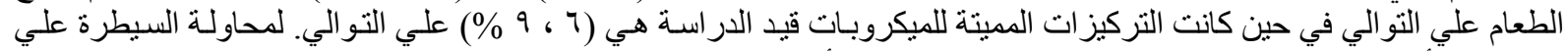

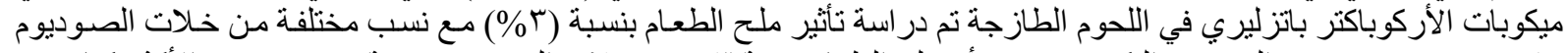

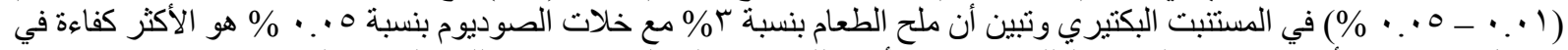

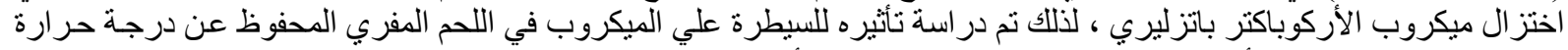

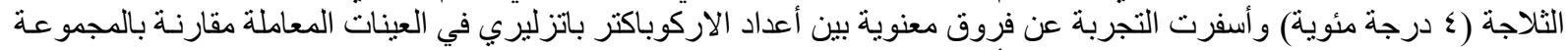

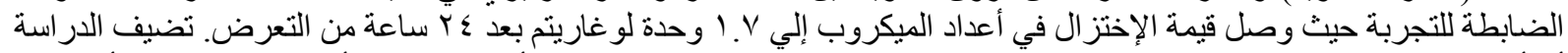

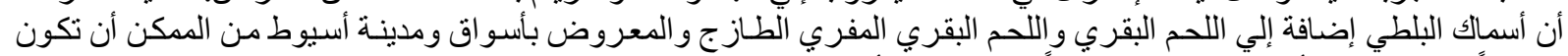

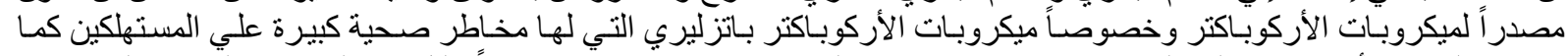

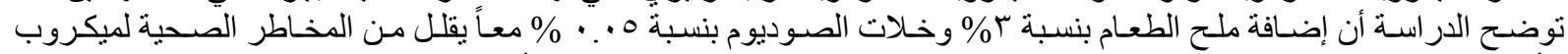

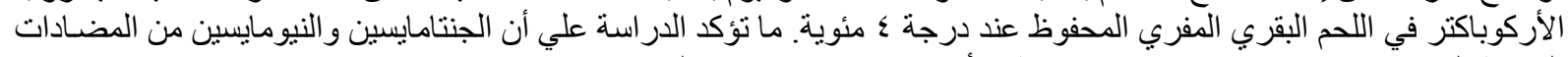
الحيوية التي يمكن استخدامها في علاج الإصابة بالأركوباكتر في الإنسان و الحيو تئران. 